\title{
Sexual Dimorphism in Patients with COVID-19: Review
}

\section{IJCRR}

Section: Healthcare

Sci. Journal Impact

Factor: 6.1 (2018)

ICV: 90.90 (2018)

(c) (i) (8)

Copyright@IJCRR

\section{Sinha S' ${ }^{1}$ Mittal S $^{2}$, Nanda B $^{3}$}

'Assistant Professor, Department of Physiology, Andhra Medical College, Visakhapatnam, Andhra Pradesh, India; 'Assistant Professor, Department of Physiology, All India Institute of Medical Sciences, Deoghar, Jharkhand, India; ${ }^{3}$ Professor \& Head, Department of Physiology, School of Medical Sciences \& Research, Greater Noida (U.P), India.

\section{ABSTRACT}

The world is facing its biggest global crisis in the 1 form of the $\mathrm{nCoV}-19$ pandemic. Females have long been supposed to have stronger immunity against all diseases including the viruses and $\mathrm{nCoV}-19$ seems to be part of a larger spectrum. The causes of less prevalence and mortality rates in females could range from a multitude of factors like stronger innate immunity to sex chromosomes to steroid hormones. Females under being diploid X chromosome undergo XCl which leads to varied manifestations of many immunomodulatory genes. The lower prevalence of COVID-19 in females could be attributable to lesser ACE2 receptors, biallelic expression of TLR7, Ddx3x, CD40L and CXCR3, higher IFN's, exaggerated expression of NEMO, IRAK1, JAK-STAT pathway, the higher number of macrophages, enhanced Th1 response and higher circulating antibodies in females. The major causes of death in a COVID-19 case has been reported to be ARDS, hypokalemia, respiratory failure, and multiorgan failure due to immune dysfunction. The increased expression of IL-6, CXCL-10, MCP-1, MIP-1a, CCL-14, and CCL-23 appear to tilt the balance in males towards an increased N/L Ratio leading to cytokine storm and ACE2 down-regulation progressing to hypokalemia, hypotensive shock and ARDS. Apart from the various protective effects existing in females in preventing the above complications, there is an upregulation of P53 and FOXP3 gene and a pro-apoptotic response which increases the Treg cells trying to bring back the female body to homeostasis.

Key Words: Coronavirus, COVID 19, Immunity, Interleukins, X chromosome inactivation

\section{INTRODUCTION}

COVID-19 is the biggest global crisis for decades. Gender may not be at the forefront of people's mind but it should not be ignored" . From Influenza pandemic of 1918, SARS of 2003, MERS of 2012, Zika virus of 2015 to COVID-19 all have a higher infectivity and fatality rate in males than in females ${ }^{2}$, even though females constitute roughly $70 \%$ of the workforce in health sector ${ }^{3}$ and are heavily involved in taking care of the sick and elderly. The observed pattern could be a reflection of behavioural or physiological differences between a male and a female. Behavioural, as in more foraging $^{2}$, reluctance towards hand hygiene, the lesser inclination for timely medical care or higher rates of alcohol and smoking in males. But even Italy and United Kingdom where the difference between the male and female smokers seems thinner had a higher number of deaths of male COVID cases. ${ }^{4}$ It could also be due to under-reporting or less access to health care in females. Physiologically, it could be a stronger immu- nity of females, sex chromosome or the steroid hormones. ${ }^{2}$ This article gives an insight into the physiological causes of gender disparity for the rapidly evolving n-CoV-19.

\section{GENDER BIAS IN COVID-19}

University of Miami Miller School of Medicine says men across the globe are at 3 times risk of dying in a hospital from COVID-19 as females. ${ }^{5}$ Chinese Centre for disease control and prevention found the male to female ratio of COVID-19 cases in China to be $1.06: 1$ and the fatality rate of $2.8 \%$ for males whereas $1.7 \%$ for females. ${ }^{6} \mathrm{JAMA}$ published an article saying of 1591 COVID-19 cases in ICU, 82\% were males ${ }^{7}$ and the case fatality ratio of male: female was $3: 1{ }^{8}$ Public health information from New York, world's largest outbreak shows deaths rate as 39/10000 in females whereas 71/10000 in males due to COVID-19. ${ }^{9}$ In Spain twice the men died due to COVID-19 as compared to females. ${ }^{10}$ Similar pattern is

\section{Corresponding Author:}

Dr. Swati Mittal, C-1104, Shipra Krishna Vista, Indirapuram, Ghaziabad (U.P), India. Contact: 9958431693; Email: drswatimittals@gmail.com

ISSN: 2231-2196 (Print)

Received: 10.07 .2020
ISSN: $0975-5241$ (Online)

Revised: 24.08 .2020
Accepted: 11.10 .2020
Published: 12.11 .2020 
mirrored in France, Germany, Iran and a few states of India. Maharashtra, the biggest epicentre of COVID-19 in India reported $39 \%$ female and $61 \%$ male cases and the death rates were $35 \%$ and $65 \%$ respectively. ${ }^{11}$ Contrary to the above data, Ministry of Health and Family Welfare, South Korea has revealed $41 \%$ of COVID-19 cases are males compared to $51 \%$ females. ${ }^{10}$

\section{IMMUNITY AND GENDER BIAS}

Sex, a biological factor not only exerts itself on physiological and anatomical differences but also to immune effector cells. Sex differences in frequency and severity for many diseases from meningococcal meningitis to tuberculosis to hepatitis$\mathrm{B}$ have long been pointed out. ${ }^{2}$ However, is COVID-19 a part of a larger pattern in which males lose out at every age or are there some characteristic differences making the prevalence, severity and mortality lesser in females?

\section{EFFECT OF SEX HORMONES}

Circulating sex hormones engage in intense physiological crosstalk with the immune effector cells (Table 1). ${ }^{12}$ All the major immune cells like T-cell, B-cell, NK-cells, dendritic cells and macrophages express estrogen receptors ER $\alpha$ and ER $\beta$ indicating that immune cells are partly controlled by female sex steroid hormones. ${ }^{13}$ Testosterone is immunoinhibitory through upregulation of anti-inflammatory cytokine Interleukin (IL)- $10^{14}$ while estrogen is immunostimulant by upregulating TNF $\alpha$ (Tumor necrosis factor-alpha) ${ }^{15}$ which helps to inhibit viral replication. Hormones also influence the regulation and modulation of the immune response and immune signalling pathways. ${ }^{16}$ Thus, the male bias becomes apparent only after sexual maturation and female disease predisposition changed with fluctuating hormones. ${ }^{17} \mathrm{But}$ it was observed that the sex bias exists in prepubertal boys and girls as well as postmenopausal women and elderly males indicating the role of factors other than steroid hormones. ${ }^{18}$

\section{EFFECT OF X CHROMOSOME AND XCI}

X-chromosome has approximately 1100 genes, the majority of which are innate and adaptive immune-related, as compared to roughly 100 genes on the Y chromosome. ${ }^{19} \mathrm{XCI}$ (X-chromosome inactivation) is the process by which $1 \mathrm{X}$ chromosome is inactivated to balance the gene expression in a diploid X female to a haploid X male. Thus, any damaging effect will have a pronounced impact on males producing the sex bias of a disease. On the other hand, females being functional mosaics, always express the beneficial X linked polymorphism and are less vulnerable to deleterious mutations. ${ }^{20}$ Roughly $15 \%$ of the genes, mostly immunomodula- tors, located at the edges of the $\mathrm{X}$ chromosome, escape XCI in a female, leading to their elevated expression. ${ }^{21,22} \mathrm{XCI}$, escape from XCI and XCI skewing (non-random inactivation where a chromosome is silenced in more than $75 \%$ of the cell ${ }^{23}$ ) may account for immune differences between the sexes. Female T cells, B cells and lymphocytes have biallelic expression as they undergo XCI escape leading to overexpression of immune-related genes. ${ }^{24}$ Further, $\mathrm{X}$ linked control mechanisms like noncoding micro-RNAs targeting 30$50 \%$ of protein-coding genes and either suppress or degrade mRNA translation account for immunological differences between genders. ${ }^{25}$

\section{WHY MALES ARE MORE PRONE FOR COVID-19?}

The characteristics of invading organism and the host interactions are important contributing factors in the final production of sex bias of a disease. Looking at the pathogenesis and immune response of the $\mathrm{nCoV}-19$, some strong characteristics in favour of the sex bias are discussed.

\section{Expression of ACE2 Receptors}

The inhaled SARS-CoV-2 likely binds to nasal epithelial cells especially, goblet cells and alveolar type 2(AT2) cells to ACE2 (Angiotensin-converting enzyme 2), a functional receptor for the virus through its protruding spike protein. ${ }^{26}$ For SARS-CoV-2 entry into a host cell, it's S protein needs to be further cleaved by host cellular proteases TMPRSS2 (Transmembrane protease, serine2) ${ }^{27} \mathrm{~A}$ study across 11 European countries has shown that men have higher ACE2 receptors in their blood than women. ${ }^{28}$ Xiyi Wei et al. through single-cell RNA sequencing of human lung tissue revealed higher expression of ACE2 in males than females. The various causes for the discrepancy could be the presence of ACE2 genes on $\mathrm{X}$-chromosome, which due to XCI is expressed in only $50 \%$ of the female cells. It was also found that the androgen receptor (AR) is co-expressed with ACE2 and TMPRSS2 and both ACE2 and TMPRSS2 were found to be positively correlated with AR not to mention that androgen expression is significantly high in males. The AR gene, that inhibits antibody production is also coded on X-chromosome and undergoes skewed XCI implicating lesser expression in females. ${ }^{29}$ Thus, the lesser the landing site for SARS-CoV-2 the lesser was the prevalence in females. Smoking, which was identified as a risk factor for COVID-19 is more prevalent in males as compared to females. ${ }^{30}$ Researchers have shown that apart from over expression of ACE2 in AT2 cells, an additional receptor for SARS-CoV-2, L-SIGN was found to be higher in former smokers. ${ }^{31,32}$ Studies have depicted 1.4 times higher chances in smokers to have severe symptoms of COVID-19 and 2.4 times more likely to have ICU admissions. ${ }^{3}$ 


\section{Role of Pattern Recognition Receptors (PRRS)}

The entry of SARS-CoV-2 into the host cell is first encountered by the antigen-presenting cells (APC) mainly macrophages and dendritic cells which identify the singlestranded mRNA by various PRRs mainly RLR (RIG like Receptors), TLR 3,4,7,8(Toll-like Receptors) and NLR (NOD-like Receptors). Each of the PRRs induces a different biological response to subsequent protein activation for eg.TLR-4 recognises the outer $\mathrm{S}$ protein component of $n C o V .{ }^{33,34}$ Studies show that in-vitro treatment of macrophages with testosterone causes a significant decrease in TLR-4 expression thus making male mice more susceptible to SARS-CoV. ${ }^{35-37}$ PRR engagement triggers the production of proinflammatory cytokines and chemokines along with IFN-1 (Interferon type 1) which is critical to the induction of antiviral immune response. TLR-7 gene which elicits strong IFN-1 production evades XCI and has a biallelic expression in female B lymphocytes, monocytes and dendritic cells ${ }^{38}$ thus providing better protection to females.

\section{Role of Interferons (INF)}

IFN $\beta$ was found to be a potent inhibitor of coronavirus and SAR-CoV-2 is much more sensitive to IFN treatment than SARS-CoV. ${ }^{39}$ Clinical data indicate a reduction of vascular leakage in ARDS (Acute Respiratory Distress Syndrome) patients with IFN $\beta 1$ a treatment. ${ }^{40}$ IFN related genes are upregulated in females as $\mathrm{Ddx} 3 \mathrm{x}$ gene necessary for IFN-1 production is located on X-chromosome and casts a dosedependent expression in females who are functional mosaics versus haploid males. ${ }^{33}$ IFNs also upregulates CD 73 (Cluster of Differentiation) in pulmonary endothelial cells which secrete anti-inflammatory adenosine helping in the maintenance of endothelial barrier function hence preventing ARDS. Again, the female hormone estrogen increases the production of IFN $\gamma$ while testosterone suppresses it. ${ }^{35}$

\section{Signalling Pathway of TLRs}

PRR engagement to viral protein and IFN-1 leads to activation of intracellular signalling pathway NF- $\mathrm{B}$ (nuclear factor kappa-light-chain-enhancer of activated B cells), through IRAK-1 (Interleukin-1 Receptor associated Kinase-1) and Myd88 (Myeloid Differentiation primary response 88) proteins leading to the production of proinflammatory cytokines. ${ }^{41} \mathrm{NEMO}(\mathrm{NF} \kappa \mathrm{B}$ Essential modulator) is a protein which activates NFKB. Both NEMO and IRAK-1 are Xlinked causing a higher expression in females. Testosterone inhibits NFאB while estrogen activates it through MyD88 which has ER $\alpha$ receptors. ${ }^{25}$ IFN-1 and various pro-inflammatory cytokines activate the JAK-STAT (Janus kinases-signal transducer and activator of transcription proteins) pathway to initiate transcription of IFN stimulated genes (ISG) leading to suppression of viral replication. Studies have depicted the upregulation of JAK-STAT in female mice. ${ }^{35}$

\section{Role of Innate Immunity}

Innate immune system of females is stronger due to increased resident macrophages, higher activation of macrophages by IFN and enhanced phagocytosis by the macrophages as compared to males. ${ }^{35}$ Low levels of female hormone $17-\beta$ estradiol also increase the levels of Fc receptors on resident macrophages whereas testosterone reduces the macrophage activation by reducing the expression as well as the sensitivity of TLR-4 receptors. NADPH oxidase complex in macrophages encoded by CYBB gene is present on $\mathrm{X}$-chromosome. A defective gene severely affects the respiratory burst of macrophages, so even if the female carries a defective gene, still the products are expressed but not in males. ${ }^{25}$

\section{Role of Adaptive Immunity}

APCs through $\mathrm{CD}^{+}{ }^{+} \mathrm{T}$-cells stimulate the $\mathrm{Th}_{1}$ cells which further stimulate $\mathrm{CD}^{+} \mathrm{T}$-cells leading to T-cell dependant antibody development. ${ }^{42} \mathrm{CD} 8^{+} \mathrm{T}$ cells have a role in directly attacking and killing virus-infected cells, in contrast to which $\mathrm{CD}^{+} \mathrm{T}$ cells prime both $\mathrm{CD} 8+\mathrm{T}$ cells and B cells. Estrogen enhances $\mathrm{Th}_{1}$ cell differentiation through IL-12 and TNF- $\alpha$ for IFN-1 mediated activity against the virus as compared to testosterone which enhances the $\mathrm{Th}_{2}$ cells through IL-4 and IL-10 which are ineffective against SARS-CoV-19. ${ }^{19}$ All antiviral genes are upregulated to a greater degree in activated female cytotoxic T-cells than in male and half of these genes have estrogen-responsive elements in their promoter region. ${ }^{35}$ TLR-7 which helps in T-cell dependant differentiation of naïve B-cell into immunoglobulin secreting cells and is an important component of antibody-mediated immune surveillance against reactivation of endogenous retroviruses undergoes XCI escape and thus has a higher expression in females, supposedly increasing the antibody response. ${ }^{43}$ Based on marker gene expression it was proved that the plasma cells were enriched in female COVID-19 patients. ${ }^{29}$ CD40L (CD40 Ligand) which is required for T cell dependant B cell activation has a biallelic expression in females due to XCI escape. ${ }^{24}$ Previous researches have elucidated that PPARs (Peroxisome proliferator-activated receptor gamma) in Tcells represses NFKB activity and IL-2 production in lymphocytes and these PPARs are abundant in naïve and activated male T-cells due to androgens as compared to females. So PPAR deficient $T$ cells in females produced increased levels of IFN $\gamma, \mathrm{TNF} \alpha$ and $\mathrm{NF} \kappa \mathrm{B} .{ }^{35}$ The above-mentioned elements lucidly explain the likely factors behind the higher prevalence of SARS-CoV-19 in males as compared to females.

\section{CAUSES OF DETERIORATION OF PATIENTS}

For about $80 \%$ of the infected patients the disease is mild and restricted to upper airways. The recruited cells clear the infection, immune response recedes and patient recovers but in about $20 \%$, the virus reaches the AT2 cells 
developing pulmonary infiltrates, severe lung disease $\mathrm{e}^{44}$ and even progresses to systemic pathology. A case report in $\mathrm{Wu}-$ han from 99 COVID-19 patients reveals that there was an increase in the total number of neutrophils and IL-6 in about $38 \%, 52 \%$ respectively and a $35 \%$ decrease of total lymphocytes. ${ }^{45}$ Another study showed the cause of death as respiratory failure, shock, and ARDS in 94\%, 81\%, and $74 \%$ of cases respectively ${ }^{46}$ and the fatality rate in males was $2.8 \%$ as compared to $1.7 \%$ in females. ${ }^{47} 39$ studies comprising 77932 COVID-19 patients, in China showed 53.3\% males and $46.7 \%$ females and men had higher odds of developing severe cases compared to women $(\mathrm{OR}=0.63,95 \% \mathrm{CI}=1.28$ 2.06). ${ }^{39}$ Karlberg et al. analysed 1755 SARS-CoV-2 patients and found the mortality rate in males higher than females $(p<0.0001) .{ }^{48}$ Jian et al. study on COVID-19 concluded that men and women had same prevalence but men cases tended to be more serious than women $(\mathrm{P}=0.035)$ and the number of men who died was 2.4 times that of women ( 70.3 vs $29.7 \%$ $\mathrm{P}=0.016) .{ }^{49}$ A meta-analysis of 206,128 confirmed cases of COVID-19 found that even though there was no difference in the proportion of male and female patients, male patients had double the odds of requiring ICU treatment on admission $(\mathrm{OR}=2.5)$ and higher odds of death $(\mathrm{OR}=1.60) .{ }^{50}$

\section{WHY IS FATALITY RATE OF COVID-19 HIGHER IN MALES?}

The probable causes are elucidated below:

\section{Significance of N/L Ratio}

Neutrophils being double-edged sword have to be regulated, otherwise can lead to tissue damage. The more severe condition patients were in, the higher were their levels of cytokines, especially IL-6 which leads to neutrophil-mediated viral clearance. ${ }^{45}$ Elevation of IL-6 $(\mathrm{p}<0.0001)$ levels was a major predictor of fatality in 150 confirmed cases of COVID-19. ${ }^{51} \mathrm{~A}$ study conducted on death cases of COVID-19 showed a reduction of blood lymphocyte percentage as a most significant and consistent trend. ${ }^{52}$ Sustained and substantial peripheral lymphopenia due to destruction of $\mathrm{T}$ cells, preferably $\mathrm{CD}^{+}$cells associated with an increase in the neutrophil count at the site of infection leads to high N/L Ratio, seen in $80 \%$ of severe COVID-19 patients. ${ }^{53,54} \mathrm{Re}-$ searchers have confirmed that TNF $\alpha$, IL-6, and other pro-inflammatory cytokines could induce lymphocyte deficiency. ${ }^{55}$ CXCL(chemokine C-X-C motif ligand)-10, a potent chemoattractant to monorytes, macrophages and activated $\mathrm{T}$ cells in response to IFN $\gamma$ could also lead to lymphopenia. ${ }^{56,24}$ IL6,7 and IL6 receptor, IL-6 ST were all found to be higher in a severe male patient as estrogen reduces neutrophil recruitment whereas testosterone increases it. ${ }^{57,29}$ The low neutrophil recruitment in females could also be due to inhibitory effects of high estradiol levels on production of CXCL-8,10 and
MCP (Monocyte Chemoattractant protein) $-1 .{ }^{56} \mathrm{~A}$ randomised controlled trial of IL- 6 blocker has been approved in patients with severe COVID-19 pneumonia. ${ }^{57}$ miRNA 223 , located on the $\mathrm{X}$ chromosome which limits the recruitment of neutrophils by downregulating the CXCL-2 and MIP (Macrophage inflammatory protein)- $1 \alpha$ genes is higher in females due to $\mathrm{XCI}$ escape ${ }^{58}$ and thus reducing the severity of disease in females. Figure 1 depicts the causes of high N/L ratio. A study found that postmenopausal women showed a greater risk of hospitalisation than non-menopausal women $(\mathrm{RR}=1.91,95 \%$ $\mathrm{CI}=1.06-3.46$ ) proving estradiol showed a protective effect against disease severity. Increased levels of IL-6 and IL-8 were found in severe COVID-19 cases $(p=0.040, p=0.033$ ) and higher levels of IL2R,6,8,10 were observed in patients who had death as outcome and estradiol levels are negatively correlated with IL2R, 6 and IL8 in luteal phase. ${ }^{59}$

\section{IMPACT OF CYTOKINE STORM}

Although the cytokines released, help the body to evade negative effects of pathogen, excessive release due to a dysfunctional immune response causes hyper inflammation and alveolar damage progressing to $\mathrm{ARDS}^{60}$. ARDS is the leading cause of mortality of COVID-19 patients. $^{51}$ A common phenomenon present in almost all severe cases was increased levels of IL-2, IL-6, IL-7, IL-8, IL-12, IL-18, GCF, MCP-1, MIP-1 $\alpha$, TNF $\alpha$, CXCL-8, CXCL-9, CXCL-10 and IFN. $^{53,44}$ release of the virus from airway epithelial cells causes pyroptosis and vascular leakage. IL-1 $\beta$, an important cytokine released during pyroptosis is highly increased in SARS-CoV-2 infection. ${ }^{61} \mathrm{~A}$ series of local inflammation starts with increased levels of IL6, IL-1 $\beta$, TNF and MCP1 which further attracts monocytes and neutrophils. These $\mathrm{CD}_{14}{ }^{+}$and $\mathrm{CD}_{16}{ }^{+}$expressing monocytes further produce chemoattractants like MIP-1 $\alpha, \mathrm{TNF} \alpha$ and CXCL-10 leading to a positive feedback cytokine storm which progresses to ARDS and multiorgan failure. ${ }^{62,63,64}$ The first autopsy of a COVID-19 patient highlighted the presence of monocytes in the lungs along with low levels of activated $T$ cells in peripheral blood. ${ }^{65}$ Whether direct virus-induced damage due to presence of ACE-2 receptors at various sites in the body or systemic cytokine storm or synergistic effects of both contributes to multiorgan dysfunction of severe COVID-19 patient needs to be addressed. ${ }^{66}$ IL-6, the main proinflammatory factor to induce the cytokine storm inhibits Th1 and favours Th17, contributing to severe lung pathology and mortality from coronavirus. ${ }^{67}$ Male COVID-19 patient exhibited a higher cytokine level of CCL (chemokine C-C motif ligand)-14, CCL-23 (monocyte, macrophage chemotactic factors) and IL-6, 7, 18 predisposing men to develop cytokine storm earlier. ${ }^{29} \mathrm{CXCL}-10$, another important factor to develop cytokine storm was found to be higher in male patients and its receptor CXCR-3 has a biallelic expression in females due to XCI escape further protecting the females. ${ }^{24,56}$ 
Estrogen suppresses monocyte-macrophage recruitment by downregulating the MCP-1 expression during inflammation and inhibiting TLR-4 mediated NFKB activation in macrophages. ${ }^{68}$ Gonadectomised male mice treated with estrogen exhibited reduced levels of TNF $\alpha$ and MCP- $1 .{ }^{37}$ Contrarily, a study revealed higher MCP-1 level in females which recruited inflammatory dendritic cells to the tracheal epithelium, conducive to virus control. ${ }^{29,69}$ CCL-3,4 which inhibits HIV1 from entering CD4 ${ }^{+}$T-cells and CXCL16 which maintains homeostasis of resident memory T-cells in the respiratory tract ${ }^{70}$ were lower in male than female patients, which also could be the cause of differential outcome. ${ }^{29,71}$

\section{DOWNREGULATION OF ACE-2 RECEPTORS}

Attachment of the $\mathrm{nCoV}$ to the ACE2 receptor causes its downregulation leading to elevated levels of Angiotensin-2 and increase the stimulation of Angiotensin-2 type-1 receptor further progressing to RAS dysfunction, hypokalemia, hypotensive shock and lung and cardiovascular injuries..$^{72-75}$ A study on 109 severe COVID-19 patients illustrated that $80 \%$ had hypokalemia due to increase in angiotensin- 2 levels $^{76}$. Another study highlighted the positive correlation of severe COVID-19 cases with hypokalemia $(95 \% \mathrm{CI}=-0.18$ to $-0.07 \mathrm{mmol} / \mathrm{L}) .{ }^{77}$ Researchers have shown that estrogen helps in upregulating the ACE2 receptors and thus protecting female patients from progressing to ARDS or multiorgan failure. Studies have also shown that ACE2 has a cardioprotective and ARDS protective role. ${ }^{78}$

\section{APOPTOSIS VERSUS NECROSIS}

IFN-1, highly expressed in females, apart from combating the viral attack, upregulated the p53 gene leading to apoptosis of the virally infected cells. While necrotic cell death spreads viral particles, apoptosis limits the virus. Progesterone promotes pro-apoptotic prostaglandin $\left(\mathrm{PGE}_{2}\right)$ while testosterone inhibits $\mathrm{PGE}_{2}{ }^{79,80}$ Testosterone also reduces the expression of FOXP-3 gene while estrogen, through its upregulation causes an increase in Treg cells thereby inhibiting the cytokine storm $^{81}$ and working towards maintenance of homeostasis. It was also found that the $\mathrm{CD}^{+} \mathrm{T}$-cells and Treg cells within the total population of T-cells are higher in females whereas males had a higher proportion of $\mathrm{CD}^{+}$ T-cells. ${ }^{44}$ Another study suggested that estrogen signalling in females directly suppresses the SARS-CoV replication via effects on cellular metabolism. ${ }^{37}$ Figure 2 shows the probable causes of reduced prevalence in a female COVID 19 patient.

\section{CONCLUSION}

Where almost all the discussions going around nCoV-19 epidemic are gender blind, the need of the hour is accurate and completely sex-disaggregated data to understand the nuances of infection, complications and death risks of COVID-19 affected males and females differently. Since this public health emergency is not gender-neutral its time that the policy decisions are made keeping gender bias in mind to fight the COVID-19 pandemic and in evaluation of effectiveness of vaccines.

\section{ACKNOWLEDGEMENTS}

Authors are deeply indebted to the scholars and publishers from whose scientific literature the text has been retrieved and which are duly cited and referenced in the reference section of the article. We are also thankful to Master Tanay Sinha for his expertise in conceptualizing and designing the figure.

\section{Conflicts of Interest: None}

Sources of Funding: NIL

\section{REFERENCES}

1. Pandemics are not gender neutral gender analysis can improve response disease outbreaks. https://unidir.org/commentary/pandemics-are-not-gender-neutral-gender-analysis-can-improveresponse-disease-outbreaks, access date: June $6^{\text {th }} 2020$.

2. Guerra-Silveira F, Abad-Franch F. Sex Bias in Infectious Disease Epidemiology: Patterns and Processes. PLoS ONE 2013;8(4): e62390.

3. Gender equity in the health workforce: Analysis of 104 countries; https://apps.who.int/iris/bitstream/handle/10665/311314/WHO-HIS-HWF-Gender-WP1-2019.1-eng. pdf, access date: May $5^{\text {th }} 2020$.

4. Gallus S, Pacifici R, Colombo P, et al. Prevalence of smoking and attitude towards smoking regulation in Italy, 2004. Eur J Cancer Prev. 2006;15(1):77 $\square 81$.

5. Nasiri J, Haddadi S, Tahvildari A, Farsi Y, Arbabi Y, Hasanzadeh S, et al. COVID-19 clinical characteristics, and sex-specific risk of mortality. Front Med (Lausanne) 2020;7:459.

6. The Novel Coronavirus Pneumonia Emergency Response Epidemiology Team. The Epidemiological Characteristics of an Outbreak of 2019 Novel Coronavirus Diseases (COVID-19) China, 2020[J]. China CDC Weekly, 2020, 2(8): 113-122.

7. Grasselli G, Zangrillo A, Zanella A, et al. Baseline Characteristics and Outcomes of 1591 Patients Infected With SARSCoV-2 Admitted to ICUs of the Lombardy Region, Italy. JAMA 2020;323(16):1574-1581.

8. Di Stadio A, Ricci G, Greco A, de Vincentiis M, Ralli M, Mortality rate and gender differences in COVID-19 patients dying in Italy: A comparison with other countries.Eur Rev Med Pharmacol Sci 2020;24(8): 4066-4067.

9. Title: The new coronavirus appears to take a greater toll on men than on women; https://www.npr.org/sections/goatsandsoda/2020/04/10/831883664/the-newcoronavirus-appears-totake-a-greater-toll-on-men-than-on-women, access date: May $12^{\text {th }} 2020$.

10. COVID-19 sex-disaggregated data tracker; https://globalhealth5050.org/covid19/sex-disaggregated-data-tracker/, access date: June $3^{\text {rd }} 2020$. 
11. Government of Maharashtra, public health department dated may $6^{\text {th }} 2020 ;$ http://ficci.in/sector/report/20565/MEDD-REPORT-1042020.pdf.

12. Zuk M, McKean KA. Sex differences in parasite infections: patterns and processes. Int J Parasitol 1996; 26: 1009-1024.

13. Klein SL, Marriott I, Fish EN. Sex-based differences in immune function and responses to vaccination. Trans R Soc Trop Med Hyg. 2015;109(1):9-15.

14. Pinzan CF, Ruas LP, Casabona-Fortunato AS, Carvalho FC, Roque-Barreira MC. Immunological basis for the gender differences in murine Paracoccidioides brasiliensis infection, PloS One 2010; (5): 10757.

15. Lotter H, Helk E, Bernin H, et al. Testosterone increases susceptibility to amebic liver abscess in mice and mediates inhibition of IFNgamma secretion in natural killer T cells. PloS One, 2013; (8): 55694.

16. Van Lunzen J, Altfeld M. Sex differences in infectious diseasescommon but neglected. J Infect Dis. 2014;209(Suppl 3): S79S80.

17. Neyrolles O, Quintana-Murci L. Sexual inequality in tuberculosis. PLoS Med. 2009;6(12):e1000199.

18. Klein SL, Marriott I, Fish EN. Sex-based differences in immune function and responses to vaccination. Trans R Soc Trop Med Hyg 2015;109(1):9-15.

19. Fish EN. The X-files in immunity: sex-based differences predispose immune responses. Nat Rev Immunol 2008;(8):737-744.

20. Migeon BR. Choosing the active $X$ : the human version of $X$ inactivation. Trends Genet TIG. 2017;33(12):899-909.

21. LibertC, Dejager L, Pinheiro I. The X chromosome in immune functions: when a chromosome makes the difference. Nat Rev Immunol, 2010; (10): 594-604.

22. Renault NKE, Pritchett SM, Howell RE, Greer WL, Sapienza C, Ørstavik KH, et al. Human X-chromosome inactivation pattern distributions fit a model of genetically influenced choice better than models of completely random choice. Eur J Hum Genet 2013;21(12):1396-1402.

23. Naqvi S, Bellott DW, Lin KS, Page DC. Conserved microRNA targeting reveals preexisting gene dosage sensitivities that shaped amniote sex chromosome evolution. Genome Res. 2018;gr.230433.117.

24. Wang J, Syrett CM, Kramer MC, Basu A, Atchison ML, Anguera MC. Unusual maintenance of $\mathrm{X}$ chromosome inactivation predisposes female lymphocytes for increased expression from the inactive X. Proc Natl Acad Sci USA. 2016 5;113(14):E2029E2038.

25. Schurz H, Salie M, Tromp G, et al. The X chromosome and sex-specific effects in infectious disease susceptibility. Hum Genomics 2019;13(2).

26. Li W, Moore MJ, Vasilieva N, Sui J, Wong SK, Berne NA, et al. Angiotensin-converting enzyme 2 is a functional receptor for the SARS. Nature 2003;426(6965):450-454.

27. Ou X, Liu Y, Lei X, et al. Characterization of spike glycoprotein of SARS-CoV-2 on virus entry and its immune cross-reactivity with SARS-CoV. Nat Commun 2020; 11:1620.

28. Irish E Sama et al. Circulating plasma concentration of Angiotensin-converting enzyme 2 in men and women with heart failure and the effect of renin-angiotensin-aldosterone inhibitors. Euro Heart J 2019;.41(19):1810-1817.

29. Xiyi Wei1, Yu-Tian Xiao1, Jian Wang1 et al.Sex Differences in Severity and Mortality Among Patients With COVID-19: Evidence from Pooled Literature Analysis and Insights from Integrated Bioinformatic Analysis;https://arxiv.org/pdf/2003.13547.

30. Vardavas CI, Nikitara K. COVID-19 and smoking: A systematic review of the evidence. Tobac Induced Dis 2020;18:20.
31. Jeffers SA, Tusell SM, Gillim-Ross L, Hemmila EM, Achenbach JE, Babcock GJ, et al.CD209L (L-SIGN) is a receptor for severe acute respiratory syndrome coronavirus. Proc Natl Acad Sci USA 2004; 101:15748-15753.

32. Cai G, Cui X, Zhu X, Zhou J, A Hint on the COVID-19 Risk: Population Disparities in Gene Expression of Three Receptors of SARS-CoV. Preprints 2020, 2020020408 doi: 10.20944/preprints202002.0408.v1).

33. Soulat D, Bürckstümmer T, Westermayer S, et al. The DEADbox helicase DDX3X is a critical component of the TANKbinding kinase 1-dependent innate immune response. EMBO J 2008;27(15):2135-2146.

34. Rabi FA, Al Zoubi MS, Kasasbeh GA, Salameh DM, Al-Nasser AD. SARS-CoV-2 and Coronavirus Disease 2019: what we know so far. Pathogens 2020; $9: 231$.

35. Gal-OM ST, Maier B, Yoshida H, et al. ImmGen report: sexual dimorphism in the immune system transcriptome. Nat Commun. 2019; 10: 4295.

36. Jennifer A. Rettew, Yvette M. Huet-Hudson, Ian Marriott, Testosterone Reduces Macrophage Expression in the Mouse of Toll-Like Receptor 4, a Trigger for Inflammation and Innate Immunity. Bio Reproduction 2008; 78 :3, 1:432-437.

37. Channappanavar R, Fett C, Mack M, Ten Eyck PP, Meyerholz DK, Perlman S. Sex-Based Differences in Susceptibility to Severe Acute Respiratory Syndrome Coronavirus Infection. J Immunol 2017; 198(10): 4046-4053.

38. Park H, Choi J. Sex-specific regulation of immune responses by PPARs. Exp Mol Med 2017; 49: e364.

39. Lokugamage KG, Schindewolf C, Menachery VD. SARSCoV-2 sensitive to type I interferon pretreatment. bioRxiv 2020.03.07.982264.

40. Bellingan G, Maksimow M, Howell DC, Stotz M, Beale R, Beatty $\mathrm{M}$, et al. The effect of intravenous interferon-beta-1a (FP1201) on lung CD73 expression and acute respiratory distress syndrome mortality: an open-label study. Lancet Respir Med 2014;2(2):98-107.

41. Yang L, Seki E. Toll-like receptors in liver fibrosis: cellular crosstalk and mechanisms. Front Physiol. 2012; 3:138.

42. Indiwani A, Srafil Y. Severe Acute Respiratory Syndrome Coronavirus 2 (SARS-CoV-2): An overview of viral structure and host response.Diabetes and Metabolic Syndrome: Clin Res Rev 2020; 14(4): 407-412.

43. Souyris M, Cenac C, Azar P, Daviaud D, Canivet A, Grunenwald $\mathrm{S}$, et al. TLR7 escapes $\mathrm{X}$ chromosome inactivation in immune cells. Sci Immunol 2018; 3(19): eaap8855.

44. Huang C, Wang Y, Li X, Ren L, Zhao J, Hu Y, et al. Clinical features of patients infected with 2019 novel coronavirus in Wuhan, This prospective study is the earliest to include an analysis of cytokine levels in severe and mild COVID-19, showing the presence of a cytokine storm analogous to that found for SARSCoV infection. China. Lancet 2020; 395: 497-506.

45. Chen N, Zhou M, Dong X, Qu J, Gong F, Han Y, et al. Epidemiological and clinical characteristics of 99 cases of 2019 novel coronavirus pneumonia in Wuhan, China: a descriptive study. Lancet, 2020; 395:507-513.

46. Du L et al. Clinical features of 85 fatal cases of COVID-19 from Wuhan: a retrospective observational Study .Am J Respir Crit Care Med. (2020), 10.1164/rccm.202003-0543OC.

47. Epidemiology Working Group for NCIP Epidemic Response. The epidemiological characteristics of an outbreak of 2019 novel coronavirus diseases (COVID-19) in China. Chin. J. Epidemiol.2020; 41: 145-151.

48. Karlberg J, Chong DS, Lai WY. Do men have a higher case fatality rate of severe acute respiratory syndrome than women do? 
Am J Epidemiol 2004; 159(3): 229-31.

49. Jin Jian-Min, Bai Peng, He Wei. Gender Differences in Patients With COVID-19: Focus on Severity and Mortality. Front Public Health. 2020;8:152.

50. Peckham H, de Gruijter N, Raine C, et al. Sex-bias in COVID-19: a meta-analysis and review of sex differences in disease and immunity. Research square Preprint. 10.21203/rs.3.rs-23651/v1.

51. Ruan Q, Yang K, Wang W, Jiang L, Song J. Clinical predictors of mortality due to COVID-19 based on an analysis of data of 150 patients from Wuhan, China. Intensive Care Med 2020;46(5):846-848.

52. Tan L, Wang Q, Zhang D, et al. Lymphopenia predicts disease severity of COVID-19: a descriptive and predictive study. Sig Transduct Target Ther 2020;5:33.

53. Qin C, Zhou L, Hu Z, et al. Dysregulation of immune response in patients with COVID-19 in Wuhan, China. Clin. Infect 2020:ciaa248.

54. Guan WJ, Ni Z, Hu Y, et al. Clinical characteristics of coronavirus disease 2019 in China. N Engl J Med 2020; 382:1708-1720.

55. Liao YC, Liang W, Chen F, et al. IL-19 induces production of IL-6 and TNF-alpha and results in cell apoptosis through TNFalpha. J Immunol 2002; 169: 4288-4297.

56. Robinson DP, Lorenzo ME, Jian W, Klein SL. Elevated 17betaestradiol protects females from influenza A virus pathogenesis by suppressing inflammatory responses, PLoS Pathog 2011; 7: e1002149.

57. Zhang S, Li L, Shen A, Chen Y, Qi Z. Rational Use of Tocilizumab in the Treatment of Novel Coronavirus Pneumonia. Clin Drug Investig 2020; 26: 1-8.

58. Deitch EA, Ananthakrishnan P, Cohen DB, Xu da Z, Feketeova E, Hauser CJ. Neutrophil activation is modulated by sex hormones after trauma-hemorrhagic shock and burn injuries. Am J Physiol Heart CircPhysiol, 2006; 291:H1456-65.

59. Ting D, Jinjin Z, Tian W, et al. A Multi-hospital Study in Wuhan, China-Protective Effects of Non-menopause and Female Hormones on SARS-CoV-2 infection. doi: https://doi.org/10.1101/ 2020.03.26.20043943.

60. Li X, Geng M, Peng Y, Meng L, Lu S. Molecular immune pathogenesis and diagnosis of COVID-19. J Pharm Anal 2020; 10(2):102-108.

61. Zhang B, Zhou X, Qiu Y, et al. Clinical characteristics of 82 death cases with COVID-19. PLOS ONE 2020. doi: 10.1371/ journal.pone. 0235458

62. Yang M. Cell pyroptosis, a potential pathogenic mechanism of 2019-nCoV infection. EJMO 2020;4(1):35-41.

63. Chen IY, Moriyama M, Chang M, Ichinohe T. Severe acute respiratory syndrome coronavirus viroporin $3 \mathrm{a}$ activates the NLRP3 inflammasome. Front Microbiol 2019;10:50.

64. Tay MZ, Poh CM, Rénia L, et al. The trinity of COVID-19: immunity, inflammation and intervention. Nat Rev Immunol 2020; 20: 363-374.

65. Xu Z, Shi L, Wang Y, et al. Pathological findings of COVID-19 associated with acute respiratory distress syndrome. Lancet Respir Med 2020;8(4):420-422.
66. Li H, Liu L, Zhamg D, et al. SARS-CoV-2 and viral sepsis: observations and hypotheses. Lancet Hypothesis 395(10235):P15171520.

67. Hotez PJ, Corry DB. The potential role of Th17immune responses in coronavirus immunopathology and vaccine induced immune enhancement. Microbes Infect 2020;22(4):165-167.

68. Murphy AJ, Guyre PM, Pioli PA. Estradiol suppresses NF-kappa $\mathrm{B}$ activation through coordinated regulation of let-7a and miR125 b in primary human macrophages. J Immunol 2010;184: 5029-5037.

69. Palomino-Segura M, Perez L, Farsakoglu Y, et al. Protection against influenza infection requires early recognition by inflammatory dendritic cells through C-type lectin receptor SIGN-R1. Nat Microbiol 2019; 4(11): 1930-40.

70. Wein AN, McMaster SR, Takamura S, et al. CXCR6 regulates localization of tissue resident memory CD8 T cells to the airways. J Exp Med 2019; 216(12): 2748-62.

71. Hudspeth K, Fogli M, Correia DV, et al. Engagement of NKp30 on Vdelta1 T cells induces the production of CCL3, CCL4, and CCL5 and suppresses HIV-1 replication. Blood 2012; 119(17): 4013-6.

72. Gu H, Xie Z, Li T, Zhang S, Lai C, Zhu P, et al. Angiotensinconverting enzyme 2 inhibits lung injury induced by the respiratory syncytial virus. Sci Rep 2016;6:19840.

73. Yumiko I, Kuba K, Penninger Josef M. The discovery of ACE2 role in acute lung injury in mice. Exp Physiol 2008;93:543-548.

74. Imai Y, Kuba K, Rao S, Huan Y, Guo F, Leong-Poi H. Angiotensin-converting enzyme 2 protects from severe acute lung failure. Nature 2005;436:112-6.

75. Kuba K, Imai Y, Penninger JM. A crucial role of angiotensinconverting enzyme 2 (ACE2) in SARS coronavirus-induced lung injury. Nat Med 2005;11:875-879.

76. Chen D, Li X, Hu C, Su F, Dai J. Hypokalemia and Clinical Implications in Patients with Coronavirus Disease 2019 (COVID-19). Preprint from medRxiv, 29 Feb 2020. DOI: 10.1101/2020.02.27.20028530 PPR: PPR115159

77. Lippi G, South AM, Henry BM. Electrolyte imbalances in patients with severe coronavirus disease in 2019 (COVID-19). Ann Clin Biochem. 2020;57(3):262-265.

78. da Silva JS, Gabriel-Costa D, Wang H, Ahmad S, Sun X, Vargas $\mathrm{J}$, et al. Blunting of cardioprotective actions of estrogen in female rodent heart linked to altered expression of cardiac tissue chymase and ACE2. J Renin Angiotensin Aldosterone Syst 2017;18(3):1470320317722270.

79. O'GarraA, Redford PS, McNab FW, Bloom CI, Wilkinson RJ, Berry MP. The immune response in tuberculosis. Annu Rev Immunol 2013; 31; 475-527.

80. Miyagi M, Morishita M, Iwamoto Y. Effects of sex hormones on production of prostaglandin E2 by human peripheral monocytes. J Periodontol, 1993;64:1075-1078.

81. Conti P, Younes A. Coronavirus COV-19/SARS-CoV-2 affects women less than men: clinical response to viral infection. J Biol Regul Homeost Agents 2020;34(2):339-343. 
Table 1: Effect of sex steroid hormones on immune effector cells

\begin{tabular}{|c|c|}
\hline ESTROGEN & TESTOSTERONE \\
\hline Increased Th1 response triggered by increased IL-12 & Increased Th2 response triggered by increased IL- 4 \\
\hline Increased production of IFN $\gamma$ and TNF $\alpha$ due to IL-12 & Reduced type 1 IFN production due to IL-10 \\
\hline Supresses IL-10 & Increases IL-10 \\
\hline Enhances macrophage activation & $\begin{array}{l}\text { Downregulates macrophage activation by reduced expression } \\
\text { of TLR-4 }\end{array}$ \\
\hline Reduced neutrophil recruitment & Increased neutrophil recruitment \\
\hline $\begin{array}{l}\text { Increased IgG and IgM production and remain longer in circu- } \\
\text { lation }\end{array}$ & Decreased $\operatorname{IgG}$ and IgM production \\
\hline Increased Treg cells due to upregulation of $\mathrm{FOXP}_{3}$ expression & Decreased Treg cells due to downregulation of $\mathrm{FOXP}_{3}$ expression \\
\hline
\end{tabular}

\section{Cause of high N/L Ratio}

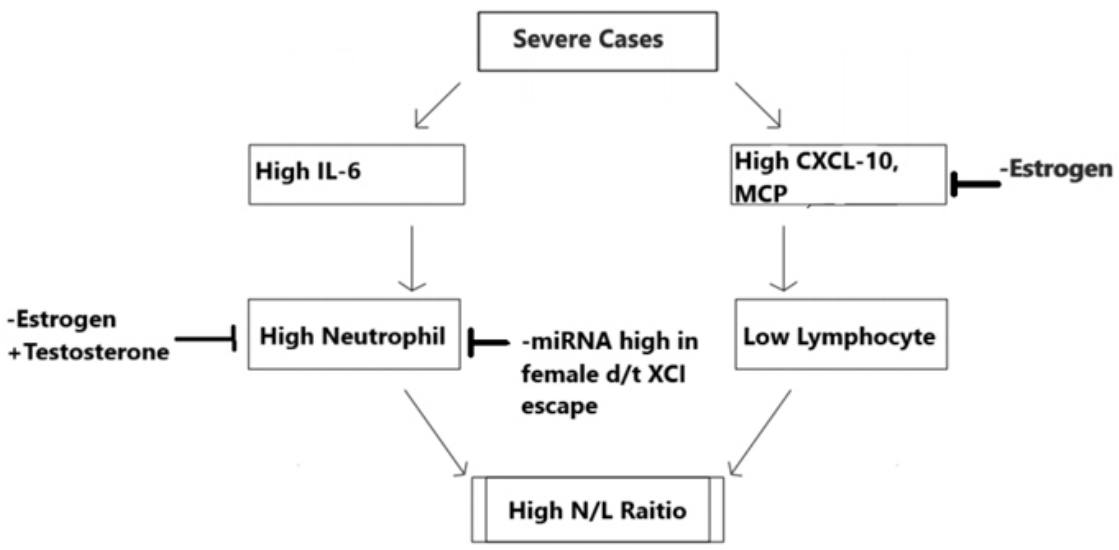

Figure 1: Shows causes of high N/L Ratio in severe cases of COVID 19.

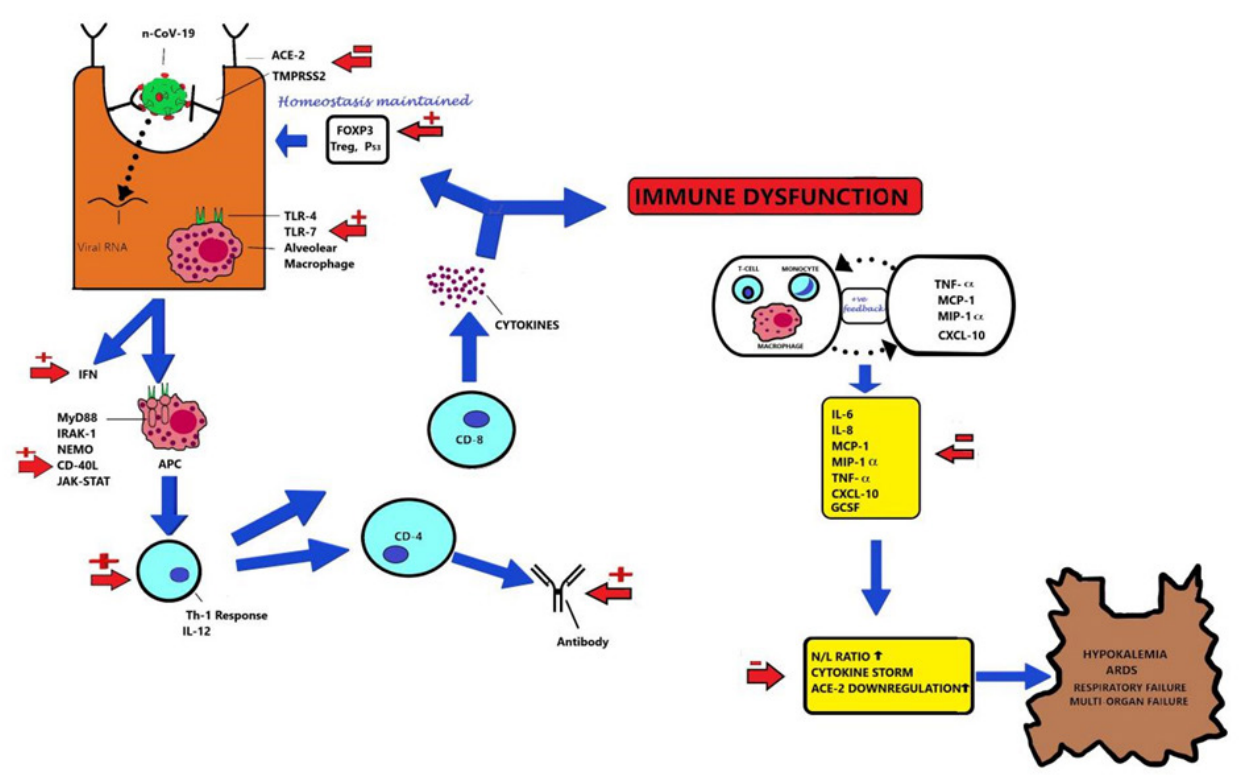

Figure 2: Summary of probable causes of reduced prevalence and severity in a female COVID-19 patient. 